Article

\title{
Toughened Poly(lactic acid)/BEP Composites with Good Biodegradability and Cytocompatibility
}

\author{
Qingguo Wang ${ }^{1,2}, * \mathbb{D}$, Yongxuan $\mathrm{Li}^{1}{ }^{1}$, Xue Zhou ${ }^{1}$, Tongyao Wang ${ }^{1}$, Liyan Qiu ${ }^{1}$, Yuanchun Gu ${ }^{1}$ \\ and Jiabing Chang ${ }^{1}$ \\ 1 Key Laboratory of Rubber-Plastics of Ministry of Education, Qingdao University of Science and Technology, \\ Qingdao 266042, China \\ 2 Shandong Provincial Key Laboratory of Rubber-Plastics, Qingdao 266042, China \\ * Correspondence: qwang@qust.edu.cn; Tel.: +86-532-8402-2418
}

Received: 27 July 2019; Accepted: 26 August 2019; Published: 28 August 2019

\begin{abstract}
Using novel biodegradable elastomer particles (BEP) prepared by the technologies of melt polycondensation, emulsification, and irradiation vulcanization, we successfully prepared advanced poly(lactic acid) (PLA)/BEP composites with higher toughness, higher biodegradability, and better cytocompatibility than neat PLA by means of the melt blending technology. The experimental results revealed that the elongation at break of the PLA/BEP composites containing 8 parts per hundred rubber (phr) by weight BEP increased dramatically from $2.9 \%$ of neat PLA to $67.1 \%$, and the notched impact strength increased from 3.01 to $7.24 \mathrm{~kJ} / \mathrm{m}^{2}$. Meanwhile, the biodegradation rate of the PLA/BEP composites increased dramatically in both soil environment and lipase solution, and the crystallization rate and crystallinity of the PLA/BEP composites increased significantly compared to those of neat PLA. The methyl thiazolyl tetrazolium (MTT) assay also showed that the viability of L929 cells in the presence of extracts of PLA/BEP composites was more than $75 \%$, indicating that the PLA/BEP composites were not cytotoxic and had better cytocompatibility than neat PLA. Research on advanced PLA/BEP composites opens up new potential avenues for preparing advanced PLA products, especially for advanced biomedical materials.
\end{abstract}

Keywords: PLA; BEP; composites; biodegradability; cytocompatibility; toughness

\section{Introduction}

Poly(lactic acid) (PLA), a bio-based biodegradable thermoplastic aliphatic polyester derived from biomass resources such as corn and sugarcane [1], has attracted a lot of attention from researchers interested in environmentally friendly materials, especially in biomedical materials. PLA has been developed for many different applications in biomedicine, including bioabsorbable screws [2,3], tissue engineering [4], stents [5-8], dental materials [9], resorbable sutures [10,11] and drug delivery systems [12,13], because of its biocompatibility, biodegradability, low immunogenicity, high strength and modulus [14-16]. However, its excessive brittleness and slow crystallization rate and biodegradation rate severely limit its further applications, especially for some specific products which require high toughness, short manufacture time, and good biocompatibility [17-19].

Therefore, some techniques have been developed to improve the performance and further applications of PLA. For instance, blending with vulcanized elastomers (such as poly (styrene-butadiene-styrene) (SBS) [20], nitrile-butadiene rubber (NBR) [21,22], thermoplastic elastomer (TPE) [23], and polyurethane (PU) [24]), nanoscale inorganic fillers (such as graphene [25,26], carbon nanotubes [27], clay [28,29], fibers [30,31]), and plasticizers (such as polyethylene glycol (PEG) [32], polypropylene glycol (PPG) [33], and acetyl tributyl citrate (ATBC) [34]) is commonly considered to improve the toughness and crystallization rate of PLA. Unfortunately, vulcanized elastomers have poor 
dispersion in a PLA matrix and have poor interface compatibility with it, decreasing the crystallization property of PLA. Inorganic fillers can enhance the stiffness obviously, although they only marginally improve the toughness or even decrease it. Low-molecular-weight plasticizers toughen PLA, but this is obtained at the cost of losing stiffness. Meanwhile, the above vulcanized elastomers, inorganic fillers, and plasticizers are not biodegradable and can deteriorate the valuable biodegradability and biocompatibility of PLA. Therefore, it is very important to find the suitable materials which can increase not only the toughness of PLA but also its crystallization rate, while not sacrificing its valuable biodegradability and biocompatibility.

In our previous work, using some bio-based monomers, such as propanediol, butanediol, succinic acid, sebacic acid, itaconic acid, and fumaric acid, we successfully fabricated novel biodegradable elastomer particles (BEP) by technologies based on melt polycondensation of aliphatic unsaturated polyester, polyester emulsified, and electron beam irradiation vulcanization [35]. It is worth noting that micro-nanoscale BEP are biodegradable due to the ester group in the macromolecular chains of the aliphatic polyester. Also, BEP has a low glass transition temperature of approximately $-50{ }^{\circ} \mathrm{C}$, controllable crosslinking density, and good compatibility with PLA, which makes it possible that BEP can be dispersed well in a PLA matrix, imparting some excellent properties to the PLA.

In this work, the novel BEP were used for the first time to prepare PLA/BEP composites. This paper focuses on the effects of BEP on toughness, crystallization, biodegradation, and cytocompatibility of PLA/BEP composites in order to obtain some advanced PLA composites that can be used for biomedical materials, food packaging, 3D printing, and more environmentally friendly products.

\section{Materials and Methods}

\subsection{Materials}

BEP with particle size of about $200 \mathrm{~nm}$ and gel content of $85 \%$ were fabricated in Qingdao University of Science and Technology (Qingdao, China); PLA (4032D) was supplied by NatureWorks LLC. (Minnetonka, MN, USA); hydrolytic stabilizer (HMV-8CA) was supplied by Nisshinbo Industries Inc. (Tokyo, Japan); lipase, $20000 \mathrm{U} / \mathrm{g}$, was supplied by Xinyu Food Additives Co., Ltd. (Wuxi, China); mixed phosphate (pH buffer), was supplied by Shanghai INESA Scientific Instrument Co., Ltd. (Shanghai, China); the mouse fibroblastic L929 cells was supplied by the type Culture Collection of the Chinese Academy of Sciences (Shanghai, China); Dulbecco's modified eagle's medium (DMEM) was supplied by Thermo Fisher Scientific Inc. (Waltham, MA, USA); fetal bovine serum (FBS), endotoxin level $\leq 10 \mathrm{EU} / \mathrm{mL}$, was supplied by Thermo Fisher Scientific Inc. (Waltham, MA, USA); penicillin-streptomycin solution (penicillin: 10000 units/mL, streptomycin: $10 \mathrm{mg} / \mathrm{mL}$ ) was supplied by Biological Industries (Beit Haemek, Israel); methyl thiazolyl tetrazolium (MTT), purity 98\%, was supplied by Sinopharm Chemical Reagent Co., Ltd. (Shanghai, China); dimethyl sulfoxide (DMSO), analytical reagent (AR), was supplied by Sinopharm Chemical Reagent Co., Ltd. (Shanghai, China).

\subsection{Preparation of $P L A / B E P$ Composites}

Firstly, PLA and BEP were placed in a vacuum-drying oven at $80^{\circ} \mathrm{C}$ for $2 \mathrm{~h}$, then PLA, BEP, and the hydrolytic stabilizer (HMV-8CA) (listed in Table 1) were mixed in a torque rheometer (RM-200C, Harbin Hapro Electric Technology Co., Ltd., Harbin, China) at a temperature of $175^{\circ} \mathrm{C}$ for $13 \mathrm{~min}$ and a rotor speed of $50 \mathrm{r} / \mathrm{min}$. PLA and PLA/BEP composite test specimens were prepared with the help of a mini-injection molder. 
Table 1. Composition of various poly(lactic acid) (PLA)/biodegradable elastomer particles (BEP) composites. Phr: parts per hundred rubber.

\begin{tabular}{ccccccc}
\hline Sample Numbers & PLA & PLA-2 & PLA-4 & PLA-6 & PLA-8 & PLA-10 \\
\hline PLA/phr & 100 & 100 & 100 & 100 & 100 & 100 \\
BEP/phr & 0 & 2 & 4 & 6 & 8 & 10 \\
HMV-8CA/phr & 0 & 0.06 & 0.12 & 0.18 & 0.24 & 0.3 \\
\hline
\end{tabular}

\subsection{Characterization}

\subsubsection{Mechanical Properties}

Tensile tests of the PLA and PLA/BEP composites were performed using a universal testing machine (UTM; GT-TCS-2000, Gotech Testing Machines Inc., Taichung, China) according to ISO 527-2-2012 at room temperature. The specimens were shaped with total length of $75 \mathrm{~mm}$, gauge length of $20 \mathrm{~mm}$, and thickness of $2 \mathrm{~mm}$. The crosshead speed was $5 \mathrm{~mm} / \mathrm{min}$. An notched Izod impact test was performed using a pendulum impact tester (GT-7045-MDH, Gotech Testing Machines Inc., Taichung, China) according to ISO 180-2000 at room temperature. The size of the impact test specimen was $80 \mathrm{~mm} \times 10 \mathrm{~mm} \times 4 \mathrm{~mm}$, and the radius of the notch base was $0.25 \pm 0.05 \mathrm{~mm}$.

\subsubsection{Surface Morphology of the Tensile Specimens and the Notched Impact Specimens}

The neck region surface of the tensile specimens and the fracture surface of the tensile specimens and notched impact specimens were observed on a scanning electron microscope (SEM; S-4800, Hitachi Ltd., Tokyo, Japan), and the surfaces were sputter-coated with a thin gold layer before observation.

\subsubsection{Crystallization Behavior and Isothermal Crystallization Kinetics}

An isothermal crystallization test was performed by a differential scanning calorimeter (DSC; 2041F1, Netzsch Group, Selb, Germany). Samples of about $10 \mathrm{mg}$ of PLA or PLA/BEP composites were heated from room temperature to $200{ }^{\circ} \mathrm{C}$ at a rate of $50^{\circ} \mathrm{C} / \mathrm{min}$ and kept at $200{ }^{\circ} \mathrm{C}$ for $3 \mathrm{~min}$ to eliminate their thermal history. Then, the samples were rapidly cooled to $115^{\circ} \mathrm{C}$. After the crystallization process was completed, the measurement was performed during a second heating from 115 to $200{ }^{\circ} \mathrm{C}$ at a rate of $10^{\circ} \mathrm{C} / \mathrm{min}$. The $T_{\mathrm{m}}, \Delta H_{\mathrm{m}}$, and $t_{\mathrm{m}}$ were calculated from the DSC melting thermograms, and the crystallinity of PLA and PLA/BEP composites was calculated by Equation (1), where $\Delta H_{0}$ is the fusion enthalpy of perfectly crystallized PLA:

$$
\text { Crystallinity }(\%)=\Delta H_{\mathrm{m}} / \Delta H_{0} \times 100 \%
$$

The heat flow data of isothermal crystallization DSC curves were converted into a fraction relative to the final crystallinity level according to the Avrami kinetic model (Equation (2)):

$$
X_{\mathrm{t}}=1-\exp \left(-K t^{n}\right)
$$

where $X_{\mathrm{t}}$ is the relative crystallinity, $K$ is the crystallization rate constant, and $n$ is the Avrami exponent. In order to estimate the values of $n$ and $K$, the double-logarithmic Equation (3) was employed to analyze the crystallization kinetics of the PLA and PLA/BEP composites.

$$
\ln \left[-\ln \left(1-X_{\mathrm{t}}\right)\right]=n \ln t+\ln K
$$

The half time of crystallization $\left(t_{1 / 2}\right)$ is defined as the time required to attain the $X_{t}=0.5$, which is calculated by Equation (4):

$$
t_{1 / 2}=\left(\frac{\ln 2}{K}\right)^{\frac{1}{n}}
$$




\subsubsection{Crystallization Morphology}

Firstly, PLA and PLA/BEP composite specimens were prepared on glass slides at $185^{\circ} \mathrm{C}$. Then, they were heated from room temperature to $200{ }^{\circ} \mathrm{C}$ at a heating rate of $50{ }^{\circ} \mathrm{C} / \mathrm{min}$ and kept at $200{ }^{\circ} \mathrm{C}$ for $3 \mathrm{~min}$. Finally, the specimens were cooled from 200 to $115^{\circ} \mathrm{C}$ at a rate of $100{ }^{\circ} \mathrm{C} / \mathrm{min}$, and their crystallization morphology was observed on a polarizing microscope (POM; BX51, Olympus Corporation, Tokyo, Japan).

\subsubsection{X-ray Diffraction Test}

X-ray diffraction patterns of PLA and PLA/BEP composite films annealed at $115^{\circ} \mathrm{C}$ for $90 \mathrm{~min}$ were obtained in the reflection mode by using an X-ray diffractometer (XRD; Ultima IV, Rigaku Corporation, Tokyo, Japan) with $\mathrm{Cu}-\mathrm{K} \alpha$ radiation wavelength $(\lambda=1.54 \AA), 40 \mathrm{kV}, 40 \mathrm{~mA}$. Scattered radiation was detected in the angular range of $10^{\circ}-30^{\circ}(2 \theta)$ at a scanning rate of $5 \% \mathrm{~min}$.

\subsubsection{Biodegradation Test}

Biodegradation Test in Soil

The dried PLA and PLA/BEP composite samples with size of $15 \mathrm{~mm} \times 15 \mathrm{~mm} \times 1 \mathrm{~mm}$ were weighed, and their corresponding weights were denoted as $W_{0}$; then, they were buried in soil. Four months later, the above samples were cleaned and dried in a vacuum-drying oven to a constant weight, which was denoted as $W_{t}$. Finally, the mass loss rate was calculated using Equation (5):

$$
\text { Mass loss rate }(100 \%)=\left(W_{0}-W_{\mathrm{t}}\right) / W_{0} \times 100 \%
$$

Biodegradation Test in Lipase Solution

The dried PLA and PLA/BEP composite samples with size of $10 \mathrm{~mm} \times 10 \mathrm{~mm} \times 1 \mathrm{~mm}$ were weighed, and their corresponding weights were denoted as $W_{0}$; then, they were placed into separate sampling tubes, and $10 \mathrm{~mL}$ of a lipase solution $(5 \mathrm{mg} / \mathrm{mL}, \mathrm{pH} 6.8)$ was added into each sampling tube at the temperature of $37^{\circ} \mathrm{C}$. The samples were incubated for 10 days. Finally, the samples in lipase solution were cleaned and dried in a vacuum-drying oven to a constant weight, which was denoted as $W_{t}$, and the mass loss rate was calculated using Equation (5) too.

\subsubsection{Surface Morphology of PLA and PLA/BEP Composites after Biodegradation}

The surface morphology of various biodegraded PLA and PLA/BEP composite samples was observed by a stereo microscope (SMZ1500, Nikon Corporation, Tokyo, Japan).

\subsubsection{Cytocompatibility Analysis}

\section{Cell Culture}

The mouse fibroblastic $\mathrm{L} 929$ cells were cultured in a humidified incubator with $5 \% \mathrm{CO}_{2}$ at $37^{\circ} \mathrm{C}$ using DMEM containing 10\% FBS, $100 \mathrm{U} / \mathrm{mL}$ penicillin, and $100 \mu \mathrm{g} / \mathrm{mL}$ streptomycin. For the MTT assay, the cells were seeded in 96-well culture plates at a density of 5000 cells per well. Then, $100 \mu \mathrm{L}$ of extracts of PLA and PLA/BEP composites at different concentrations $(0.25,0.5,1,2,5 \mathrm{mg} / \mathrm{mL})$ was added to the culture medium. Meanwhile, $100 \mu \mathrm{L}$ phenol $(0.5 \%)$ was used as a positive control, and $100 \mu \mathrm{L}$ phosphate-buffered saline (PBS, pH 7.4) was used as a negative control. Non-treated control cells (blank) were analyzed to compare the growth inhibition. The entire plate was observed in an inverted microscope (CKX41, Olympus Corporation, Tokyo, Japan) after 24, 48, and $72 \mathrm{~h}$ of incubation.

\section{MTT Assay}

After 24, 48 and $72 \mathrm{~h}$ of incubation with extracts medium, $10 \mu \mathrm{L}$ of MTT solution with $5 \mathrm{mg} / \mathrm{mL}$ was added to each well, and the plates were incubated at $37^{\circ} \mathrm{C}$ in $5 \% \mathrm{CO}_{2} /$ air for $4 \mathrm{~h}$. Next, the medium 
was removed, and $150 \mu \mathrm{L}$ of DMSO was added to each wells. The optical density (OD) was measured in an absorbance microplate reader (ELx800, BioTek Instruments Inc., Winooski, VT, USA) at $490 \mathrm{~nm}$. All experiments were repeated three times. Finally, cell viability was calculated using the Equation (6):

$$
\text { Cell viability }=\frac{O D_{\text {experiment }}-\mathrm{OD}_{\text {blank }}}{O D_{\text {negative }}-\mathrm{OD}_{\text {blank }}}
$$

\section{Results and Discussion}

\subsection{Effects of BEP on the Toughness of PLA/BEP Composites}

Figure 1 presents the relationship between BEP content and the toughness of the PLA/BEP composites. With the increase of BEP concentration, the impact strength and elongation at break of the PLA/BEP composites increased significantly. The elongation at break of the PLA/BEP composites containing 8 phr BEP increased dramatically from $2.9 \%$ of the neat PLA to $67.1 \%$, and the notched impact strength increased from 3.01 to $7.24 \mathrm{~kJ} / \mathrm{m}^{2}$. These phenomena can be explained by the multiple crazing theory [36]. On the one hand, the well-dispersed BEP in the PLA matrix have an effect on stress concentration during the tensile process, inducing the initiation and extension of crazing in the PLA matrix. Both crazing initiation and crazing extension can consume energy. Accordingly, the polymer absorbs a high amount of energy and avoids a highly localized strain process, which leads to higher elongation at break and impact strength $[37,38]$. On the other hand, crazing extension will terminate when they meet with some other BEPs, thereby preventing the generation of cracking in the PLA matrix and increasing the toughness of the PLA/BEP composites [39]. However, when BEP loading increases to $10 \mathrm{phr}$, elongation at break and impact strength of the PLA/BEP composites slowly decrease because excessive BEP tend to aggregate in the PLA matrix, thus weakening crazing initiation and crazing extension in the PLA matrix.

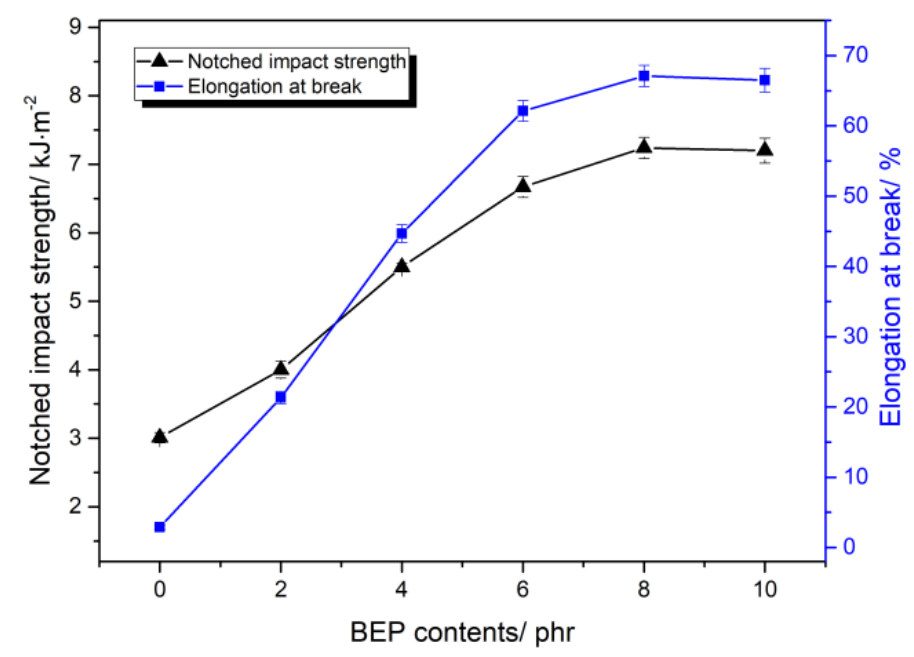

Figure 1. Impact strength and elongation at break of PLA/BEP composites with various BEP amounts.

Figure 2 shows some SEM micrographs of the impact fracture surfaces of neat PLA and PLA-8 composites. In Figure 2a, the impact fracture surface of neat PLA is smooth, and there is no plastic deformation, indicating that a brittle fracture process occurred in neat PLA. However, there are some voids and a certain roughness on the impact fracture surface of the PLA- 8 composites (Figure 2b), which indicates that a ductile fracture process occurred in the PLA- 8 composites. The above results show that BEP dispersed in the PLA matrix can absorb the impact energy and prevent further fractures in the PLA matrix. 

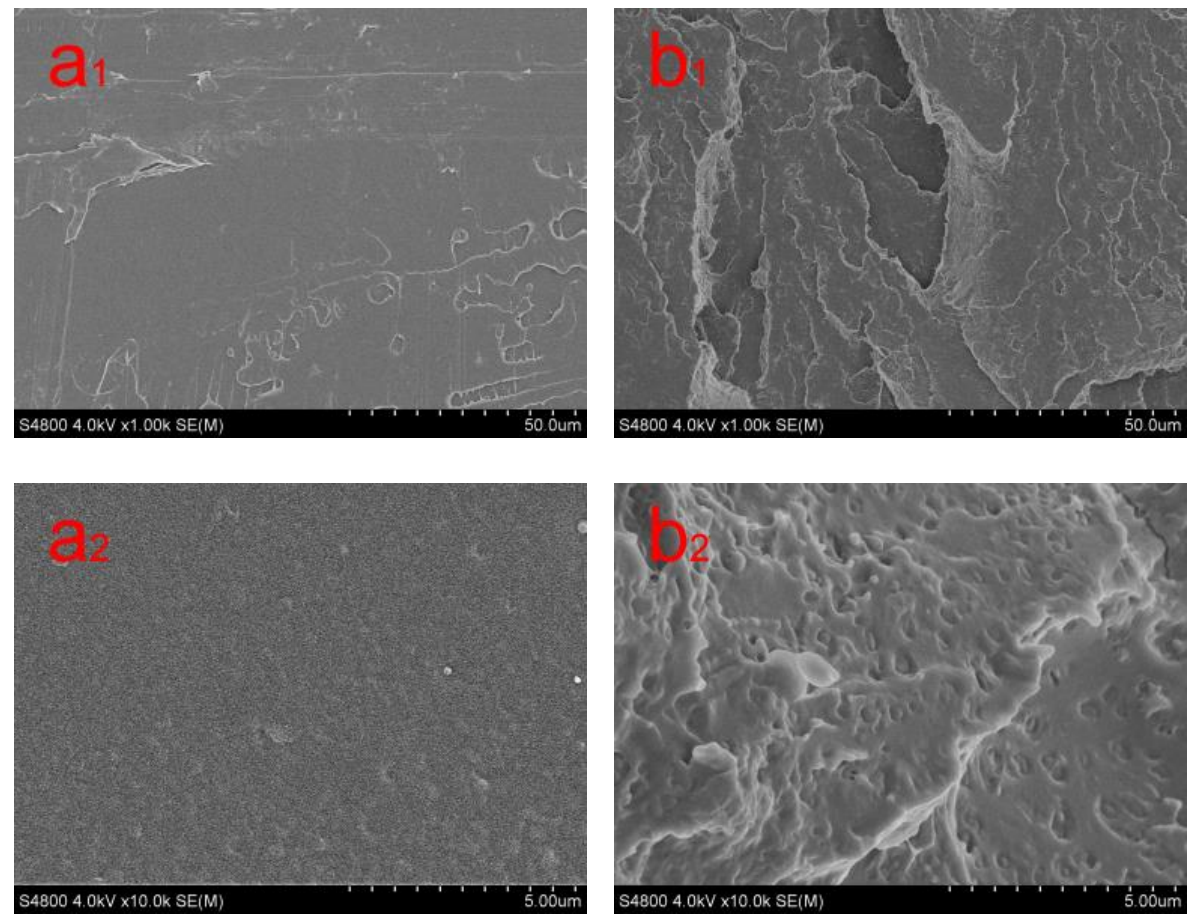

Figure 2. SEM micrographs of the impact fracture surface of neat PLA and PLA-8 composites,

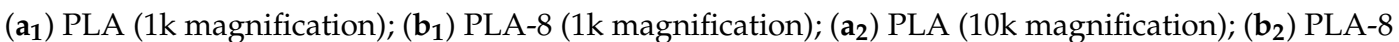
(10k magnification).

Figure 3 shows some SEM micrographs of the tensile neck region surface of neat PLA and PLA/BEP composites. In Figure $3 \mathrm{a}$, the tensile neck region surface of neat PLA is smooth, whereas the tensile neck region surface of the PLA/BEP composites exhibits the stress whitening phenomenon (in Figure $3 b, c$ ), which indicates that the crack propagation paths were highly bifurcated and crack propagation absorbed a considerable amount of strain energy before the PLA matrix was completely destroyed.
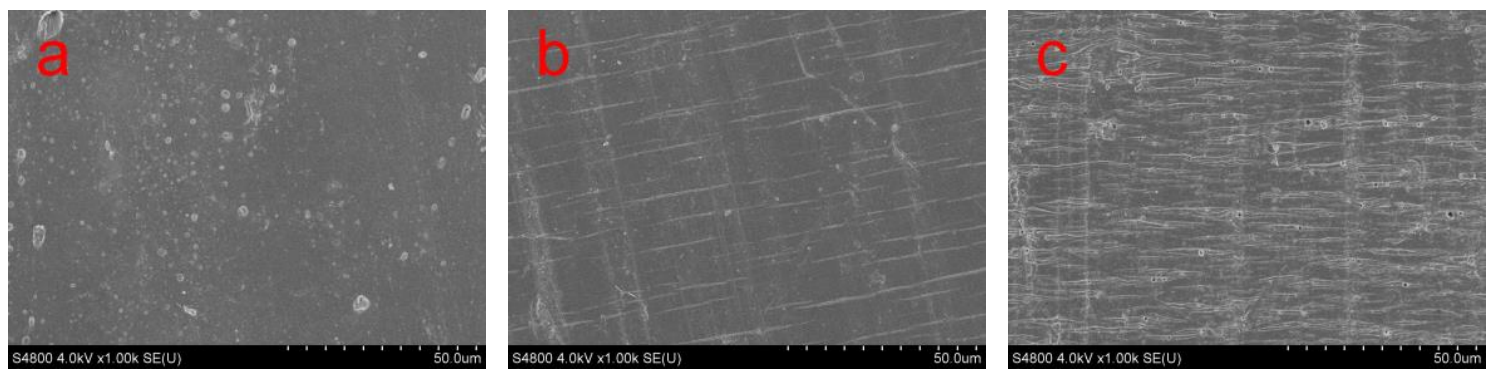

Figure 3. SEM micrographs of the neck regions of neat PLA and PLA/BEP composites at $1 \mathrm{k}$ magnification, (a) PLA; (b) PLA-4; (c) PLA-8.

Figure 4 shows some SEM micrographs of tensile fracture surface of neat PLA and PLA/BEP composite specimens, indicating a large plastic deformation of the PLA matrix in the PLA/BEP composites, while the fracture surface of neat PLA is smooth, which confirms the above conclusions that BEP in the PLA matrix have the effect of absorbing energy and causing a ductile fracture process in the PLA matrix. 

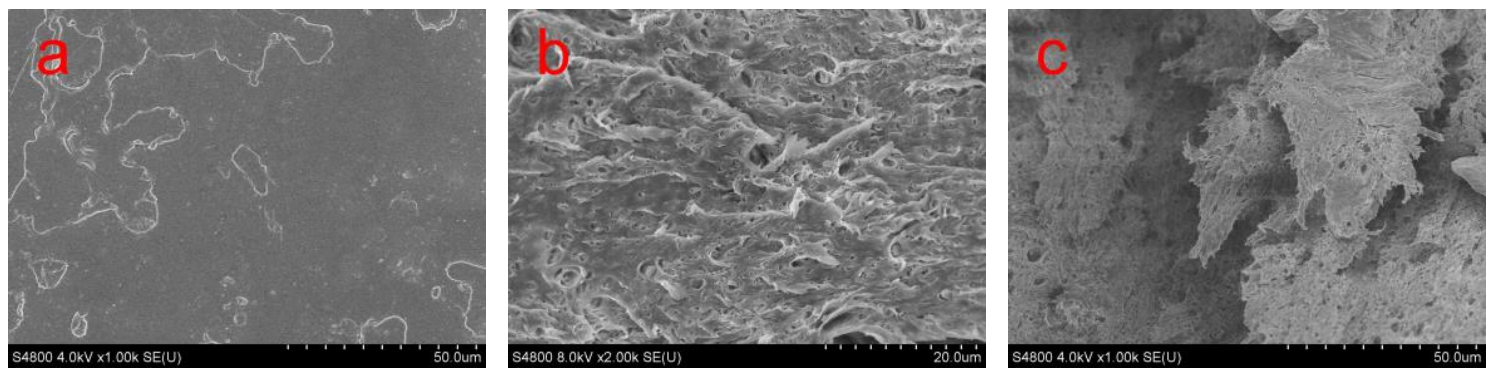

Figure 4. SEM micrographs of the tensile fracture surface of neat PLA and PLA/BEP composites at 2k magnification, (a) PLA; (b) PLA-4; (c) PLA-8.

On the basis of the above SEM micrographs, we inferred that BEP toughen PLA by forming large interfaces; strong interfacial interactions between the PLA matrix and BEP deform the PLA matrix and increase the absorption of energy until the PLA matrix breaks. Thus, the impact strength and elongation at break of the PLA/BEP composites increase considerably with increasing BEP loading.

\subsection{Effects of BEP on the Crystallization Properties of PLA/BEP Composites}

The isothermal crystallization kinetic parameters of neat PLA and PLA/BEP composites are listed in Table 2. As shown in Table 2, the $t_{1 / 2}$ of PLA- 8 is $41 \%$ faster than that of neat PLA, while the crystallinity increases of $50.6 \%$, which means that BEP can accelerate the crystallization rate and increase the crystallinity of PLA. The $n$ values of the PLA/BEP composites are higher than that of neat PLA, indicating that the PLA/BEP composites present more extensive three-dimensional crystal growth than neat PLA during the crystallization process. The $K$ value of PLA- 8 also increases of $59.6 \%$ compared to that of neat PLA. Therefore, BEP act as an effective nucleating agent and accelerate the crystallization rate of PLA by providing nucleation sites and facilitating crystal growth.

Table 2. Isothermal crystallization kinetic parameters of various PLA/BEP composites.

\begin{tabular}{cccccccc}
\hline $\begin{array}{c}\text { Sample } \\
\text { Numbers }\end{array}$ & $\boldsymbol{t}_{\mathbf{1} / \mathbf{2}} / \mathbf{m i n}$ & $\boldsymbol{n}$ & $\boldsymbol{K}$ & $\boldsymbol{T}_{\mathbf{m}} /{ }^{\circ} \mathbf{C}$ & $\boldsymbol{\Delta} \boldsymbol{H}_{\mathbf{m}} / \mathbf{J} \cdot \mathbf{g}^{-\mathbf{1}}$ & Crystallinity/\% & $\boldsymbol{t}_{\mathbf{m}} / \mathbf{m i n}$ \\
\hline PLA & 12.07 & 2.69 & 0.047 & 165.4 & 28.41 & 30.55 & 16 \\
PLA-4 & 10.22 & 2.81 & 0.051 & $159.7,167.0$ & 40.67 & 45.48 & 14 \\
PLA-8 & 7.11 & 2.89 & 0.075 & $160.3,167.3$ & 39.62 & 46.01 & 10 \\
\hline
\end{tabular}

Figure 5 shows the melting DSC thermograms curves of neat PLA and PLA/BEP composites. Interestingly, the PLA/BEP composites have two melting peaks at about 160 and $167^{\circ} \mathrm{C}$, while the neat PLA has only one melting peak at $165.4^{\circ} \mathrm{C}$, which indicates that two kinds of crystal forms appeared in the PLA/BEP composites crystallization process [40]. As is well known, the $\alpha$ crystal form of PLA, which grows during melting or cold crystallization, is its most common and stable crystal form. Zhang et al. found that the $\alpha^{\prime}$ crystal form coexists with the $\alpha$ crystal form when $T_{\mathrm{c}}$ is between 100 and $120^{\circ} \mathrm{C}$ [41]. It can be speculated that BEP in the PLA matrix accelerated the formation of the $\alpha^{\prime}$ crystal form and that $160^{\circ} \mathrm{C}$ is the melting point of the $\alpha^{\prime}$ crystal form, while $167^{\circ} \mathrm{C}$ is the melting point of the $\alpha$ crystal form.

Figure 6 shows some XRD patterns of neat PLA and PLA/BEP composites. Two strong diffraction peaks appeared at $16.92^{\circ}$ and $19.22^{\circ}$ in the XRD patterns of neat PLA, which correspond to two kinds of diffractions of the (200)/(110) crystal plane and (203) crystal plane, respectively [42]. However, the diffraction peaks of the (200)/(110) crystal plane in the XRD patterns of PLA-4 and PLA- 8 composites shifted to low $2 \theta$, from $16.92^{\circ}$ to $16.82^{\circ}$ and $16.76^{\circ}$, respectively. These shifts were observed during the formation of the $\alpha$ and $\alpha^{\prime}$ crystal phases in the range from 100 to $120^{\circ} \mathrm{C}$. In addition, BEP in the PLA matrix increased the intensity of the XRD patterns, indicating that BEP had the effect of improving the crystallinity of PLA. 


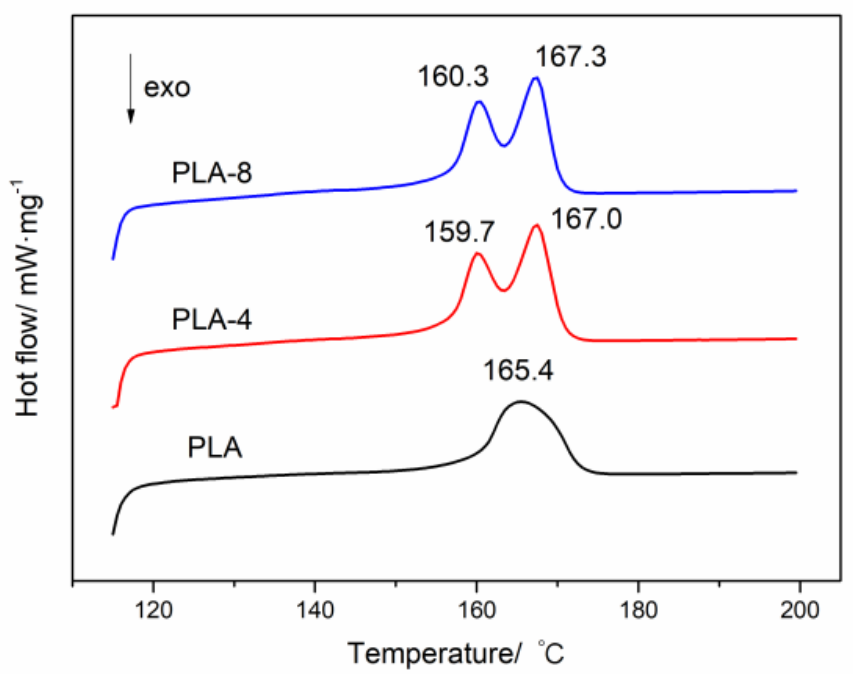

Figure 5. Melting DSC thermograms curves of neat PLA and PLA/BEP composites.

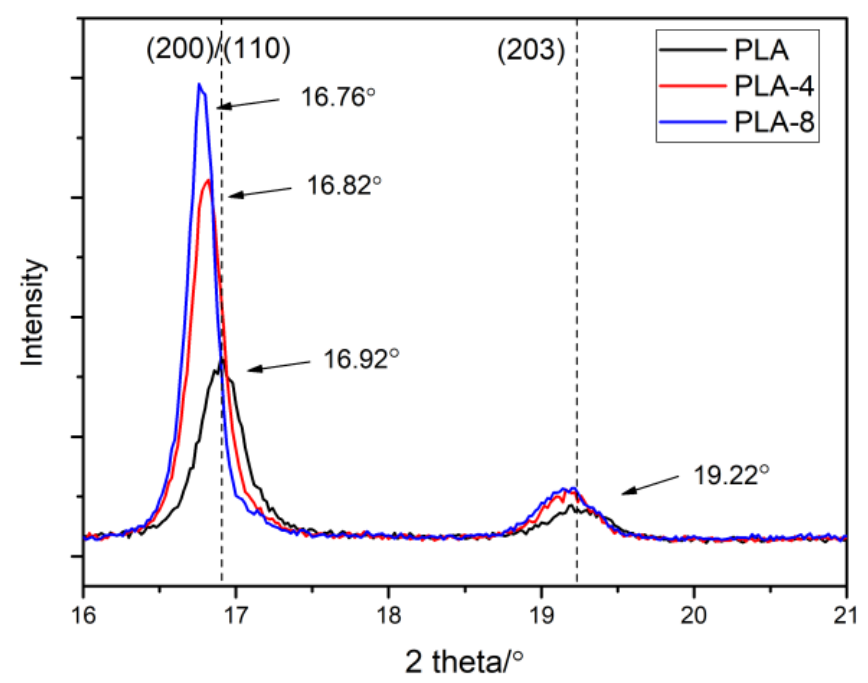

Figure 6. XRD patterns of neat PLA and PLA/BEP composite films annealed at $115^{\circ} \mathrm{C}$ for $90 \mathrm{~min}$.

Figure 7 presents some polarizing optical micrographs of neat PLA and PLA-8 composites with various isothermal crystallization times at $115^{\circ} \mathrm{C}$. It can be seen that no crystal of neat PLA (Figure 7a) was observed during $5 \mathrm{~min}$ of isothermal crystallization, and a small number of crystals grew at a slow crystallization rate after $10 \mathrm{~min}$ of isothermal crystallization. Meanwhile, the number of those crystals did not increase, whereas the size of the spherulites increased after $15 \mathrm{~min}$ of isothermal crystallization. However, many small spherulites of PLA-8 composites with a morphology different from that of neat PLA grew after 5 min of crystallization, and the spherulites radius of PLA- 8 was smaller than that of neat PLA (Figure $7 \mathrm{~b}$ ), which possibly can be explained by the fact that the twisting of lamellae resulted in varied crystalline structures of PLA [43]. After $10 \mathrm{~min}$ of isothermal crystallization, the number of spherulites of PLA-8 increased rapidly, and after $15 \mathrm{~min}$, the spherulites of PLA- 8 nearly covered the entire field. It can be inferred that BEP act as a nucleating agent in the PLA crystallization process and accelerate PLA crystallization rate. 

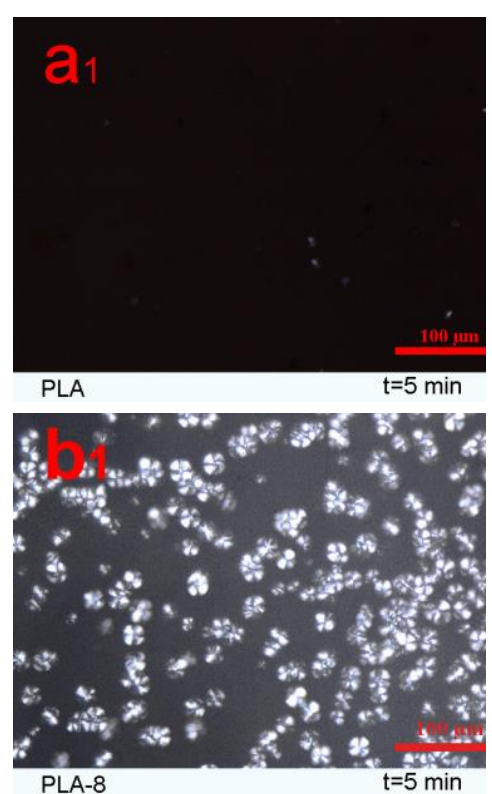

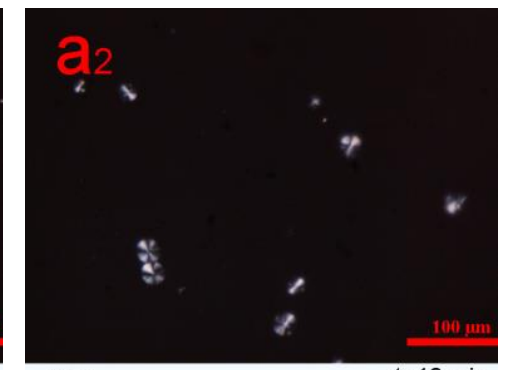

PLA

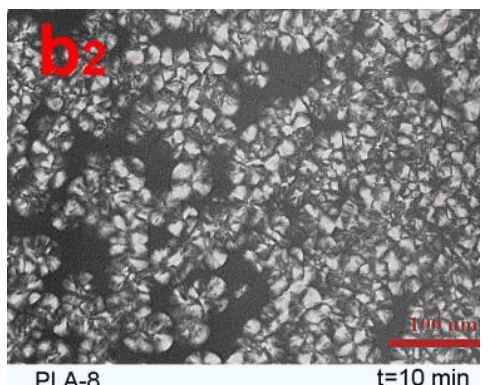

PLA-8
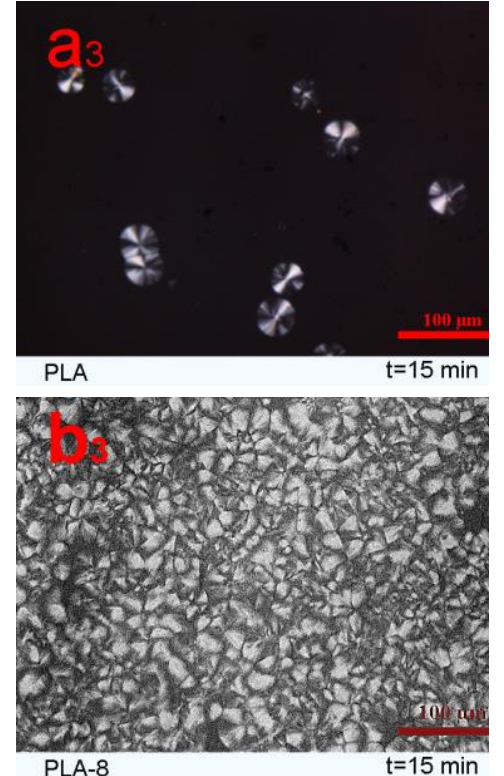

Figure 7. Polarizing optical micrographs of the spherulitic morphology of neat PLA and PLA-8 composites, (a) PLA; (b) PLA-8.

\subsection{Effects of BEP on the Biodegradation of PLA/BEP Composites}

In general, the soil burying test and composting test are performed to evaluate the biodegradability of plastics in natural environments [44,45]. The degradation of PLA in soil or compost occurs through the following process. During the initial phases of degradation, PLA chains with high molecular weight are hydrolyzed to form chains with lower molecular weight, and this reaction can be accelerated by acids or bases and is also affected by temperature and moisture [46]. Also, some microorganisms in the compost catalyze the degradation, probably through the hydrolytic scission of ester groups into an acid and an alcohol. This process enables the conversion of the chains with low molecular weights to $\mathrm{CO}_{2}$, water, and humus.

Figure 8 shows some stereo microscope images of neat PLA and PLA/BEP composites degraded in soil for 4 months. The surface of neat PLA after degradation remained smooth and clean. However, extensive mildew was observed on the surfaces of the PLA/BEP composites, among which the PLA-8 sample had the most extensive mildew growth, indicating that the amount of mildew increased significantly on the PLA/BEP composites with increasing BEP loading.
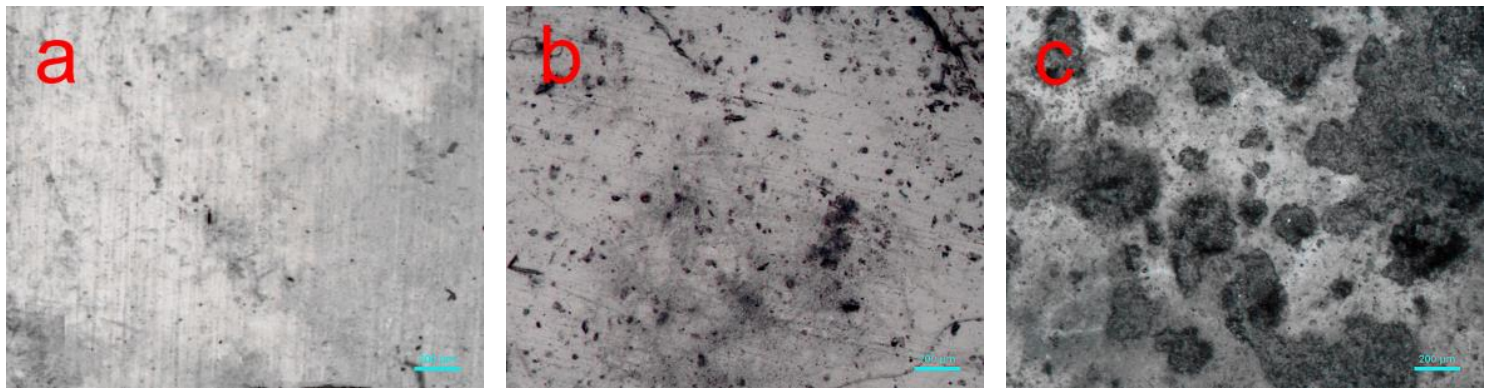

Figure 8. Stereo microscope photos of neat PLA and PLA/BEP composites after 4 months of degradation in soil, (a) PLA; (b) PLA-4; (c) PLA-8. 
Figure 9 presents the mass loss of neat PLA and PLA/BEP composites after 4 months in soil. With increasing BEP loading, the mass loss of the PLA/BEP composites markedly increased, and the mass loss of the PLA-10 increased 3.6 times (from $0.31 \%$ to $1.44 \%$ ).

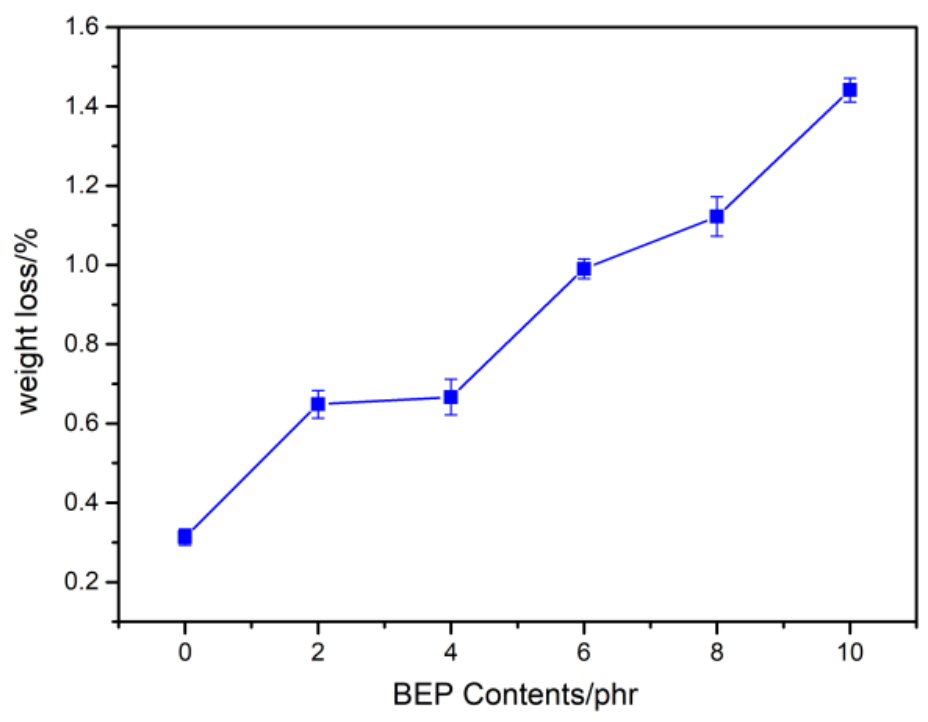

Figure 9. Mass loss of neat PLA and PLA/BEP composites after degradation in soil for 4 months.

Pranamuda et al. found that microorganisms which can degrade PLA are rare in soil, and only one strain of such microorganisms (Amycolatopsis sp.) was isolated [47]. Therefore, neat PLA has a low degradation rate in soil. However, the PLA/BEP composites presented a better degradability than neat PLA, which indicates that BEP exhibit good degradability and produce some low-molecular-weight aliphatic acids and aliphatic alcohols in the degradation process [35]. Thereby, the presence of BEP in the PLA matrix increase the degradation rates of the PLA/BEP composites.

Figure 10 presents the mass loss of neat PLA and PLA/BEP composites degraded in a lipase solution for 10 days. With the increase of BEP loading, the mass loss of the PLA/BEP composites significantly increased, and the mass loss of PLA-10 increased 1.46 times (from $1.3 \%$ to $3.2 \%$ ) compared to that of neat PLA. In order to explain this phenomenon, we present a degradation schematic of the PLA/BEP composites in lipase solution (Figure 11). The large specific surface area of BEP can increase the contact area between the PLA/BEP composites and the lipase solution, making the PLA/BEP composites more susceptible to biodegrade by hydrolysis and enzymatic activity. Meanwhile, BEP are readily exposed to enzymes, and enzymes can easily break apart the ester bonds in BEP. Therefore, BEP easily degrade into acids and alcohols. As a catalyst, the $\mathrm{H}^{+}$in the acid accelerates the degradation process of the PLA matrix, and the voids and gaps formed after BEP degradation can also facilitate the penetration of the lipase solution into the PLA matrix [48]. Thus, the degradation rates of the PLA/PEP composites increases. 


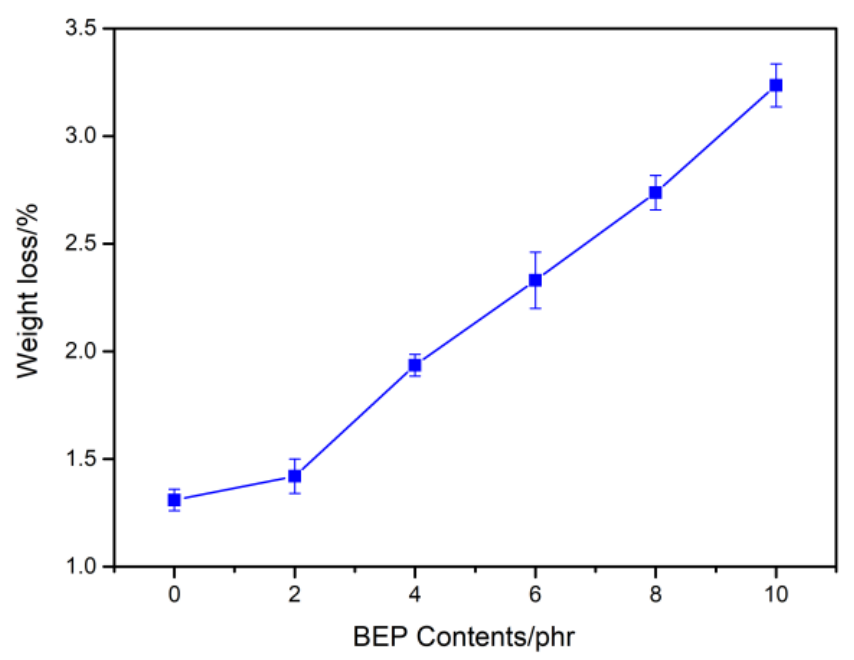

Figure 10. Mass loss of neat PLA and PLA/BEP composites after degradation in lipase solution for 10 days.

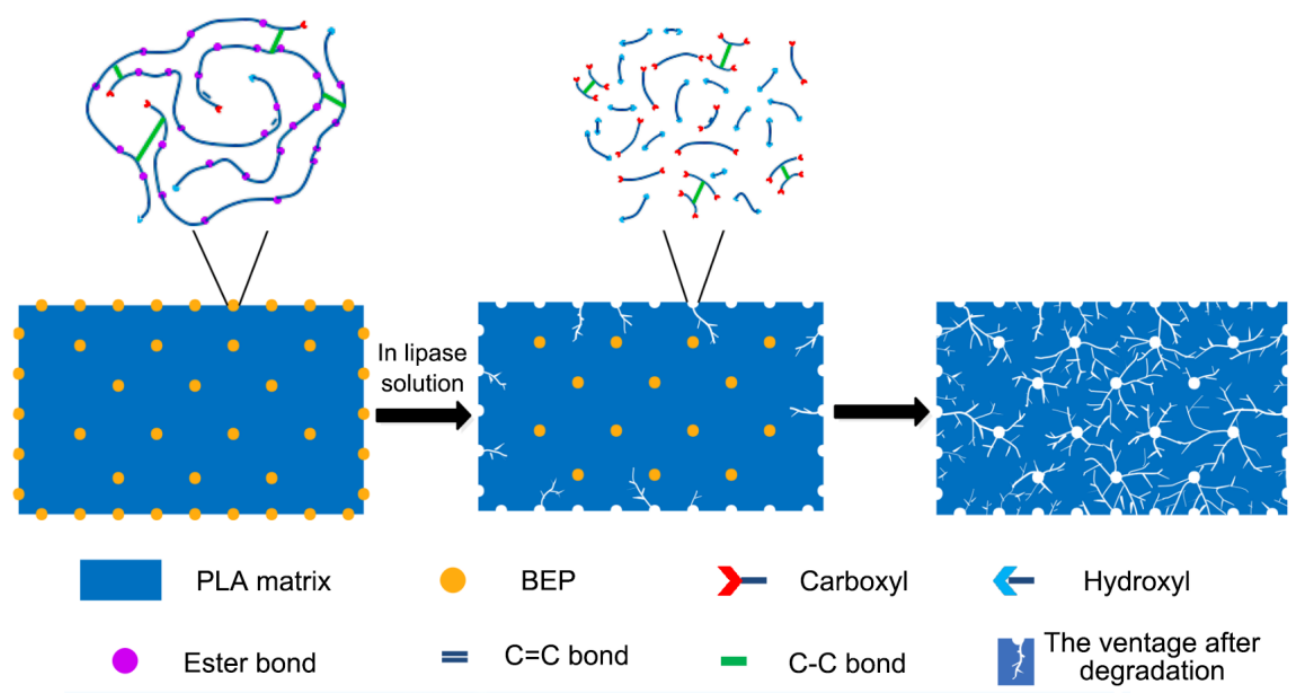

Figure 11. Degradation schematic of the PLA/BEP composites in a lipase solution.

\subsection{Effects of BEP on the Cytocompatibility of PLA/BEP Composites}

Figure 12 presents the results of the MTT assay which was conducted to check cell viability after 24,48 , and $72 \mathrm{~h}$ of incubation with different concentrations of extracts. Cell viability in the presence of extracts of the PLA/BEP composites was higher than in the presence of extracts of neat PLA (more than $75 \%$ in the presence of all the PLA/BEP composite extracts). At the time point of $72 \mathrm{~h}$, the viability of cells cultured in the presence of all extracts of the PLA/BEP composites was higher than that measured at $24 \mathrm{~h}$ for the corresponding extracts. Figure 13 presents microscopic images of the control groups and the experiment groups treated with $2 \mathrm{mg} / \mathrm{mL}$ of extracts of the PLA/BEP composites. The cell morphologies were determined on the basis of cell distribution and mean cell aspect ratio, with L929 cells having an aspect ratio greater than 1.5 [49]. The addition of extracts did not cause considerable changes in the morphology of the cells, such as rounding or shrinking, and all the images are more or less identical to that of the negative control. So, it can be concluded that the PLA/BEP composite extracts at the tested concentration do not exert cytotoxic effects on cell proliferation, and the PLA/BEP composites have better cytocompatibility than PLA, which makes them a potential material for biomedicine. 


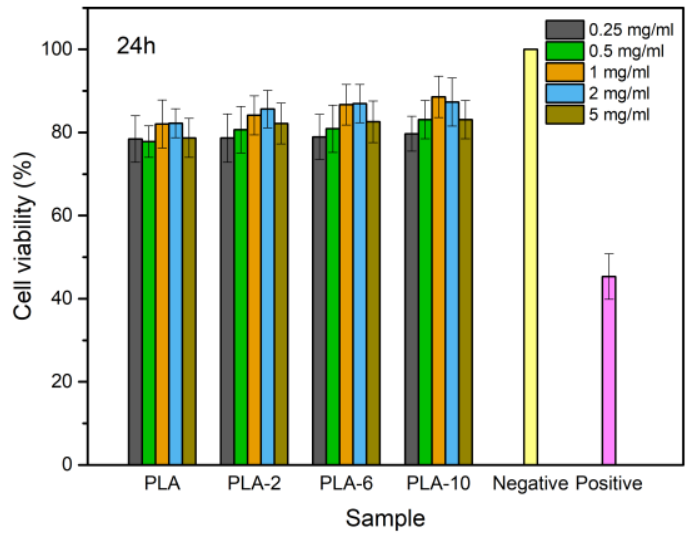

(a)

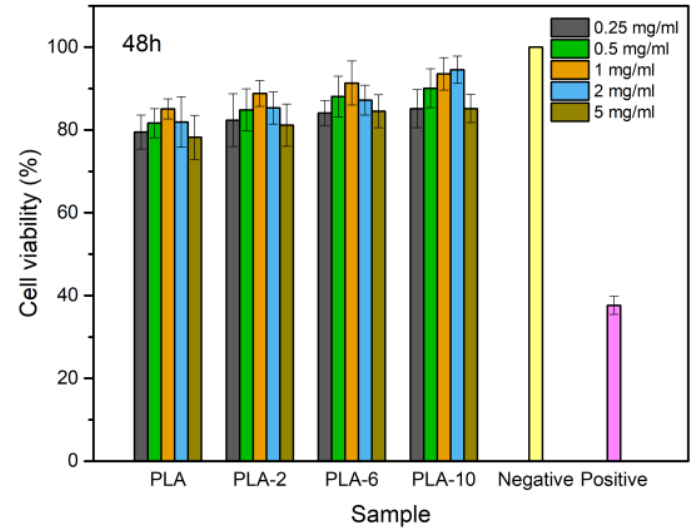

(b)

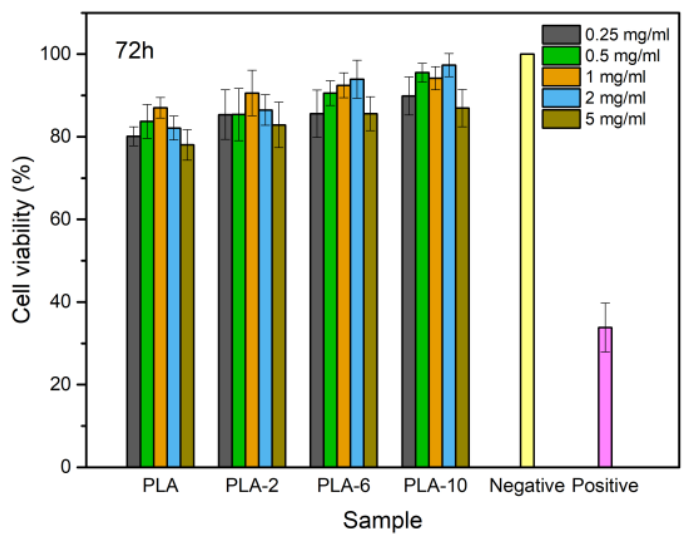

(c)

Figure 12. Cell viability of L929 cells in the presence of extracts of neat PLA and PLA/BEP composites at different concentrations and incubation times: (a) $24 \mathrm{~h}$; (b) 48 h; (c) $72 \mathrm{~h}$.
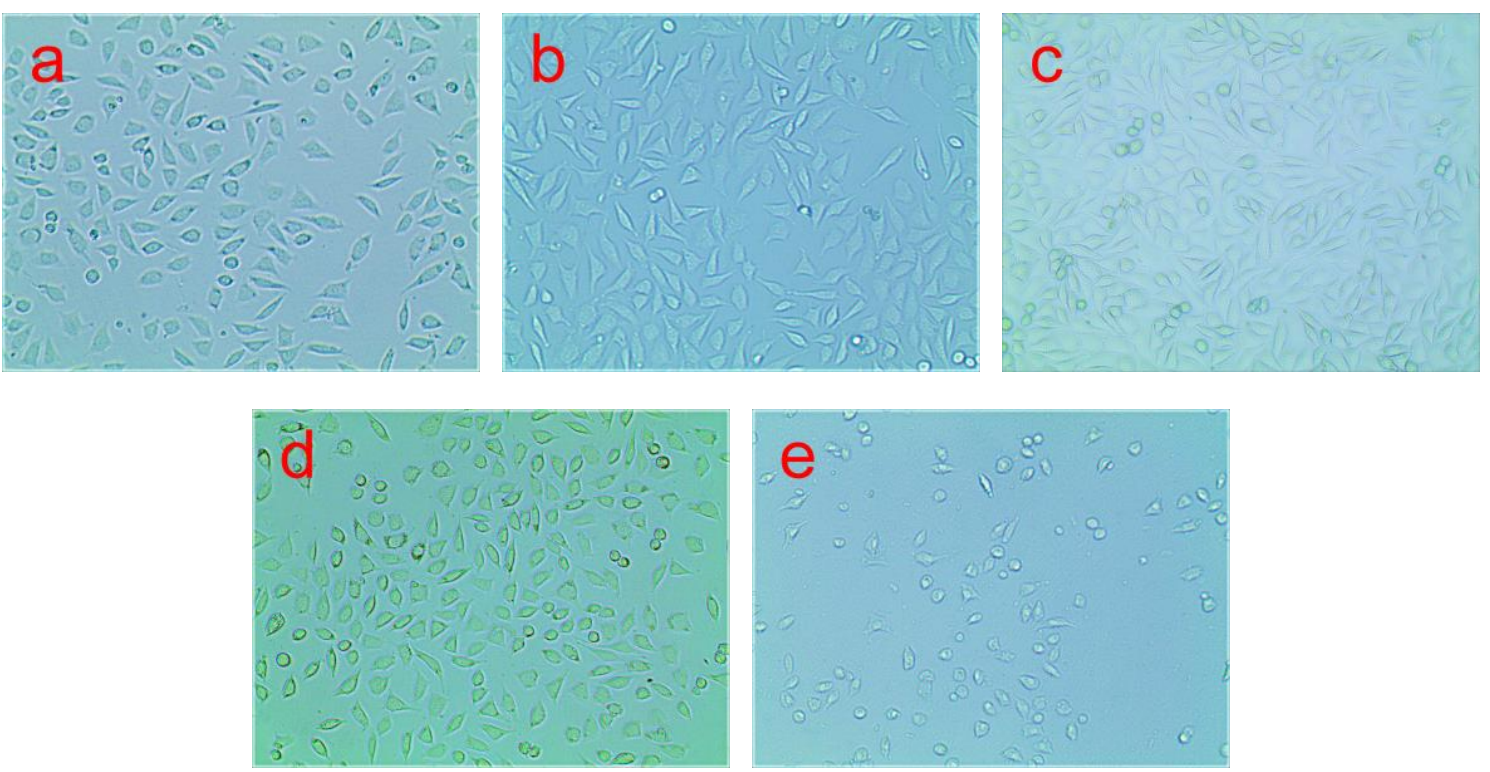

Figure 13. Micrograph of L929 cells at 100 magnification: (a) 24 h PLA-10; (b) 48 h PLA-10; (c) 72 h PLA-10; (d) negative control, after $24 \mathrm{~h}$; (e) positive control, after $24 \mathrm{~h}$. 


\section{Conclusions}

Using micro-nanoscale BEP prepared by melt polycondensation, emulsification, and irradiation vulcanization, we successfully prepared advanced PLA/BEP composites by a simple melt blending technology. Elongation at break of the PLA/BEP composites containing $8 \mathrm{phr}$ BEP increased dramatically from $2.9 \%$ of neat PLA to $67.1 \%$, and the notched impact strength increased from 3.01 to $7.24 \mathrm{~kJ} / \mathrm{m}^{2}$. The crystallization rate and crystallinity of the PLA/BEP composites were higher than those of neat PLA. Meanwhile, two kinds of crystal forms were formed in the PLA/BEP composites crystallization process. It is worth noting that BEP had the effect of improving the biodegradation rate of the PLA/BEP composites in both soil environment and lipase solution. Also, the PLA/BEP composites showed better cytocompatibility. This research is very important for preparing some advanced PLA products which meet the requirements of high toughness, high biodegradability, good cytocompatibility, and short manufacturing time.

Author Contributions: Conceptualization, Q.W.; Formal analysis, Q.W., Y.L., X.Z., T.W., L.Q., Y.G., and J.C.; Writing-original draft, Y.L. and X.Z.; Writing—review \& editing, Q.W.

Funding: This work was funded by the National Natural Science Foundation of China (grant numbers 51773104, 51373085); and the Key Research and Development Project in Shandong Province of China (grant number 2017GGX20138).

Conflicts of Interest: The authors declare no conflict of interest.

\section{References}

1. Nampoothiri, K.M.; Nair, N.R.; John, R.P. An overview of the recent developments in polylactide (PLA) research. Bioresour. Technol. 2010, 101, 8493-8501. [CrossRef] [PubMed]

2. Felfel, R.M.; Ahmed, I.; Parsons, A.J.; Rudd, C.D. Bioresorbable composite screws manufactured via forging process: Pull-out, shear, flexural and degradation characteristics. J. Mech. Behav. Biomed. Mater. 2013, 18, 108-122. [CrossRef] [PubMed]

3. Sakaguchi, M.; Kobayashi, S. Effect of extrusion drawing and twist-orientation on mechanical properties of self-reinforced poly(lactic acid) screws. Adv. Compos. Mater. 2016, 25, 443-456. [CrossRef]

4. Manavitehrani, I.; Fathi, A.; Wang, Y.W.; Maitz, P.K.; Dehghani, F. Reinforced poly(propylene carbonate) composite with enhanced and tunable characteristics, an alternative for poly(lactic acid). ACS Appl. Mater. Interfaces 2015, 7, 22421-22430. [CrossRef] [PubMed]

5. Zhao, N.; Lv, Z.R.; Ma, J.; Zhu, C.W.; Li, Q. Fabrication of hydrophilic small diameter vascular foam scaffolds of poly(E-caprolactone)/polylactic blend by sodium hydroxide solution. Eur. Polym. J. 2019, 110, 31-40. [CrossRef]

6. Lin, M.H.; Firoozi, N.; Tsai, C.T.; Wallace, M.B.; Kang, Y.Q. 3D-printed flexible polymer stents for potential applications in inoperable esophageal malignancies. Acta Biomater 2019, 83, 119-129. [CrossRef] [PubMed]

7. Wiebe, J.; Nef, H.M.; Hamm, C.W. Current Status of Bioresorbable Scaffolds in the Treatment of Coronary Artery Disease. J. Am. Coll. Cardiol 2014, 64, 2541-2551. [CrossRef]

8. Mi, H.Y.; Salick, M.R.; Jing, X.; Jacques, B.R.; Crone, W.C.; Peng, X.F.; Turng, L.S. Characterization of thermoplastic polyurethane/polylactic acid (TPU/PLA) tissue engineering scaffolds fabricated by microcellular injection molding. Mater. Sci. Eng. C. 2013, 33, 4767-4776. [CrossRef]

9. Tomlin, E.M.; Nelson, S.J.; Rossmann, J.A. Ridge preservation for implant therapy: A review of the literature. Open Dent 2014, 8, 66-76. [CrossRef]

10. Maharana, T.; Mohanty, B.; Negi, Y.S. Melt-solid polycondensation of lactic acid and its biodegradability. Prog. Polym. Sci. 2009, 34, 99-124. [CrossRef]

11. Jain, R.A. The manufacturing techniques of various drug loaded biodegradable poly(lactide-co-glycolide) (PLGA) devices. Biomaterials 2000, 21, 2475-2490. [CrossRef]

12. Langer, R. Drug delivery and targeting. Nature 1998, 392, 5-10. [PubMed]

13. Peres, C.; Matos, A.I.; Conniot, J.; Sainz, V.; Zupančič, E.; Silva, J.M.; Graça, L.; Gaspar, R.S.; Préat, V.; Florindo, H.F. Poly(lactic acid)-based particulate systems are promising tools for immune modulation. Acta Biomater. 2017, 48, 41-57. [CrossRef] [PubMed] 
14. Anderson, J.M.; Shive, M.S. Biodegradation and biocompatibility of PLA and PLGA microspheres. Adv. Drug Deliv. Rev. 2012, 64, 72-82. [CrossRef]

15. Lasprilla, A.J.R.; Martinez, G.A.R.; Lunelli, B.H.; Jardini, A.L.; Maciel, R. Poly-lactic acid synthesis for application in biomedical devices - A review. Biotechnol. Adv. 2012, 30, 321-328. [CrossRef] [PubMed]

16. Nagarajan, V.; Mohanty, A.K.; Misra, M. Perspective on Polylactic Acid (PLA) based Sustainable Materials for Durable Applications: Focus on Toughness and Heat Resistance. ACS Sustainable Chem. Eng. 2016, 4, 2899-2916. [CrossRef]

17. Anderson, K.S.; Schreck, K.M.; Hillmyer, M.A. Toughening Polylactide. Polym. Rev. 2008, 48, 85-108. [CrossRef]

18. Saeidlou, S.; Huneault, M.A.; Li, H.B.; Park, C.B. Poly (lactic acid) crystallization. Prog. Polym. Sci. 2012, 37, 1657-1677. [CrossRef]

19. Murariu, M.; Dubois, P. PLA composites: From production to properties. Adv. Drug Deliv. Rev. 2016, 107, 17-46. [CrossRef]

20. Zhang, H.; Chen, Z.; Zheng, Z.; Zhu, X.M.; Wang, H.T. Shape memory polymer hybrids of SBS/dl-PLA and their shape memory effects. Mater. Chem. Phys. 2013, 137, 750-755. [CrossRef]

21. Maroufkhani, M.; Katbab, A.; Liu, W.C.; Zhang, J.W. Polylactide (PLA) and acrylonitrile butadiene rubber (NBR) blends: The effect of ACN content on morphology, compatibility and mechanical properties. Polymer 2017, 115, 37-44. [CrossRef]

22. Talbamrung, T.; Kasemsook, C.; Sangtean, W.; Wachirahuttapong, S.; Thongpin, C. Effect of Peroxide and Organoclay on Thermal and Mechanical Properties of PLA in PLA/NBR Melted Blend. Energy Procedia 2016, 89, 274-281. [CrossRef]

23. Zaman, H.U.; Song, J.C.; Park, L.S.; Kang, I.K.; Park, S.Y.; Kwak, G.; Park, B.S.; Yoon, K.B. Poly (lactic acid) blends with desired end-use properties by addition of thermoplastic polyester elastomer and MDI. Polym. Bull 2011, 67, 187-198. [CrossRef]

24. Raja, M.; Ryu, S.H.; Shanmugharaj, A.M. Thermal, mechanical and electroactive shape memory properties of polyurethane (PU)/poly (lactic acid) (PLA)/CNT nanocomposites. Eur. Polym. J. 2013, 49, 3492-3500. [CrossRef]

25. Pinto, A.M.; Cabral, J.; Tanaka, D.A.P.; Mendes, A.M.; Magalhães, F.D. Effect of incorporation of graphene oxide and graphene nanoplatelets on mechanical and gas permeability properties of poly (lactic acid) films. Polym. Int. 2013, 62, 33-40. [CrossRef]

26. Fu, Y.; Liu, L.S.; Zhang, J.W. Manipulating Dispersion and Distribution of Graphene in PLA through Novel Interface Engineering for Improved Conductive Properties. ACS Appl. Mater. Interfaces 2014, 6, 14069-14075. [CrossRef]

27. Seligra, P.G.; Lamanna, M.; Famá, L. PLA-fMWCNT Bionanofilms with High Modulus and Great Properties to Apply in Packaging and Biomedicine. Procedia Mater. Sci. 2015, 8, 383-390. [CrossRef]

28. Darie, R.N.; Pâslaru, E.; Sdrobis, A.; Pricope, G.M.; Hitruc, G.E.; Poiată, A.; Baklavaridis, A.; Vasile, C. Effect of Nanoclay Hydrophilicity on the Poly (lactic acid)/Clay Nanocomposites Properties. Ind. Eng. Chem. Res. 2014, 53, 7877-7890. [CrossRef]

29. Zhou, Y.H.; Lei, L.; Yang, B.; Li, J.B.; Ren, J. Preparation of PLA-based nanocomposites modified by nano-attapulgite with good toughness-strength balance. Polym. Test 2017, 60, 78-83. [CrossRef]

30. Ding, W.D.; Jahani, D.; Chang, E.; Alemdar, A.; Park, C.B.; Sain, M. Development of PLA/cellulosic fiber composite foams using injection molding: Crystallization and foaming behaviors. Comp. Part A 2016, 83, 130-139. [CrossRef]

31. Hossain, K.M.Z.; Ahmed, I.; Parsons, A.J.; Scotchford, C.A.; Walker, G.S.; Thielemans, W.; Rudd, C.D. Physico-chemical and mechanical properties of nanocomposites prepared using cellulose nanowhiskers and poly(lactic acid). J. Mater. Sci. 2012, 47, 2675-2686. [CrossRef]

32. Arrieta, M.P.; López, J.; Rayón, E.; Jiménez, A. Disintegrability under composting conditions of plasticized PLA-PHB blends. Polym. Degrad. Stab 2014, 108, 307-318. [CrossRef]

33. Piorkowska, E.; Kulinski, Z.; Galeski, A.; Masirek, R. Plasticization of semicrystalline poly(L-lactide) with poly(propylene glycol). Polymer 2006, 47, 7178-7188. [CrossRef]

34. Courgneau, C.; Ducruet, V.; Avérous, L.; Grenet, J.; Domenek, S. Nonisothermal crystallization kinetics of poly(lactide)-effect of plasticizers and nucleating agent. Polym. Eng. Sci. 2013, 53, 1085-1098. [CrossRef] 
35. Wang, Q.G.; Zai, Y.Y.; Yang, D.J.; Qiu, L.Y.; Niu, C.Q. Bio-based elastomer nanoparticles with controllable biodegradability. RSC Adv. 2016, 6, 102142-102148. [CrossRef]

36. Bucknall, C.B.; Smith, R.R. Stress-whitening in high-impact polystyrenes. Polymer 1965, 6, 437-446. [CrossRef]

37. Mat Desa, M.S.Z.; Hassan, A.; Arsad, A.; Arjmandi, R. Effect of core-shell rubber toughening on mechanical, thermal, and morphological properties of poly (lactic acid)/multiwalled carbon nanotubes nanocomposites. J. Appl. Polym. Sci. 2019, 136, 47756. [CrossRef]

38. Sun, Y.; He, C. Biodegradable "core-shell" rubber nanoparticles and their toughening of poly (lactides). Macromolecules 2013, 46, 9625-9633. [CrossRef]

39. Bucknall, C.B.; Clayton, D.; Keast, W.E. Rubber-toughening of plastics. 2. creep mechanisms in HIPS/PPO blends. J. Mater. Sci. 1972, 7, 1443-1453. [CrossRef]

40. Murariu, M.; Dechief, A.L.; Ramy-Ratiarison, R.; Paint, Y.; Raquez, J.M.; Dubois, P. Recent advances in production of poly (lactic acid) (PLA) nanocomposites: A versatile method to tune crystallization properties of PLA. Nanocomposites 2015, 1, 71-82. [CrossRef]

41. Zhang, J.M.; Duan, Y.X.; Sato, H.; Tsuji, H.; Noda, I.; Yan, S.; Ozaki, Y. Crystal Modifications and Thermal Behavior of Poly (1-lactic acid) Revealed by Infrared Spectroscopy. Macromolecules 2005, 38, 8012-8021. [CrossRef]

42. Nam, J.Y.; Ray, S.S.; Okamoto, M. Crystallization Behavior and Morphology of Biodegradable Polylactide/Layered Silicate Nanocomposite. Macromolecules 2003, 36, 7126-7131. [CrossRef]

43. Nitta, K.H.; Takayanagi, M. Tensile yield of isotactic polypropylene in terms of a lamellar-cluster model. J. Polym. Sci. Part B: Polym. Phys. 2000, 38, 1037-1044.

44. Karamanlioglu, M.; Houlden, A.; Robson, G.D. Isolation and characterization of fungal communities associated with degradation and growth on the surface of poly(lactic) acid (PLA) in soil and compost. Int. Biodeterior. Biodegrad. 2014, 95, 301-310. [CrossRef]

45. Karamanlioglu, M.; Robson, G.D. The influence of biotic and abiotic factors on the rate of degradation of poly(lactic) acid (PLA) coupons buried in compost and soil. Polym. Degrad. Stab. 2013, 98, 2063-2071. [CrossRef]

46. Ho, K.L.G.; Pometto, A.L.; Gadea-Rivas, A.; Briceño, J.A.; Rojas, A. Degradation of Polylactic Acid (PLA) Plastic in Costa Rican Soil and Iowa State University Compost Rows. J. Environ. Polym. Degrad. 1999, 7, 173-177. [CrossRef]

47. Tokiwa, Y.; Calabia, B.P. Biodegradability and biodegradation of poly(lactide). Appl. Microbiol. Biotechnol. 2006, 72, 244-251. [CrossRef] [PubMed]

48. Lee, S.H.; Kim, S.H.; Han, Y.K.; Kim, Y.H. Synthesis and Degradation of End-Group-Functionalized Polylactide. J. Polym. Sci. Part A: Polym. Chem. 2001, 39, 973-985. [CrossRef]

49. VandeVord, P.J.; Matthew, H.W.T.; DeSilva, S.P.; Mayton, L.; Wu, B.; Wooleyl, P.H. Evaluation of the biocompatibility of a chitosan scaffold in mice. J. Biomed. Mater. Res. 2002, 59, 585-590. [CrossRef]

(C) 2019 by the authors. Licensee MDPI, Basel, Switzerland. This article is an open access article distributed under the terms and conditions of the Creative Commons Attribution (CC BY) license (http://creativecommons.org/licenses/by/4.0/). 